\title{
Online Monitoring Oxidative Products and Metabolites of Nicotine by Free Radicals Generation with Fenton Reaction in Tandem Mass Spectrometry
}

\author{
Shih-Shin Liang, ${ }^{1,2}$ Yow-Ling Shiue, ${ }^{3}$ Chao-Jen Kuo, ${ }^{4}$ Su-Er Guo, ${ }^{5}$ \\ Wei-Ting Liao, ${ }^{2}$ and Eing-Mei Tsai ${ }^{1,4}$ \\ ${ }^{1}$ Center for Resources, Research and Development, Kaohsiung Medical University, 100 Shih-Chuan 1st Road, Kaohsiung 80708, Taiwan \\ ${ }^{2}$ Department of Biotechnology, College of Life Science, Kaohsiung Medical University, 100 Shih-Chuan 1st Road, \\ Kaohsiung 80708, Taiwan \\ ${ }^{3}$ Institute of Biomedical Science, National Sun Yat-Sen University, 70 Lienhai Road, Kaohsiung 80424, Taiwan \\ ${ }^{4}$ Graduate Institute of Medicine, Kaohsiung Medical University, 100 Shih-Chuan 1st Road, Kaohsiung 80708, Taiwan \\ ${ }^{5}$ Department of Nursing, Chang Gung University of Science and Technology, 2 Chia-Pu Road, Chiayi 61363, Taiwan
}

Correspondence should be addressed to Shih-Shin Liang; liang0615@kmu.edu.tw and Eing-Mei Tsai; tsaieing@yahoo.com

Received 18 April 2013; Accepted 22 May 2013

Academic Editors: H.-W. Chang, L.-Y. Chuang, S. Guleria, and S. Yasmin

Copyright (C) 2013 Shih-Shin Liang et al. This is an open access article distributed under the Creative Commons Attribution License, which permits unrestricted use, distribution, and reproduction in any medium, provided the original work is properly cited.

In general, over $70 \%$ absorbed nicotine is metabolized to cotinine and trans-3'-hydroxycotinine by cytochrome oxidase $\mathrm{P} 450$, and nicotine is also a major addictive and the psychoactive component in cigarettes. As a xenobiotic metabolism, hydrophobic compounds are usually converted into more hydrophilic products through enzyme systems such as cytochrome oxidase P450, sulfotransferases, and UDP-glucuronosyltransferases to deliver drug metabolites out of the cell during the drug metabolic process. In this study, an electrodeless electrochemical oxidation (EEO) reaction via Fenton reaction by producing free radical to react with nicotine to immediately monitor the oxidative products and metabolic derivatives of nicotine by tandem mass spectrometer (MS) is done. Fenton reaction generates free radicals via ferrous ion $\left(\mathrm{Fe}^{2+}\right)$ and hydrogen peroxide $\left(\mathrm{H}_{2} \mathrm{O}_{2}\right)$ to oxidize DNA and to degrade proteins in cells. In the EEO method, the oxidative products of nicotine including cotinine, cotinine- $N$-oxide, trans-3'-hydroxycotinine, nornicotine, norcotinine, 4-oxo-4-(3-pyridyl)-butanoic acid, 4-hydroxy-4-(3-pyridyl)-butanoic acid, and nicotine- $N^{\prime}$-oxide were detected by tandem mass spectrometer to simulate the changes of nicotine and its derivatives in a time-dependent manner.

\section{Introduction}

A free radical can be defined as an atom, molecule, or ion with an unpaired valence electron [1] and has a strong reactivity to attack other molecules or generate new free radicals by atom transfer radical polymerization (ATRP) [2]. Free radicals, such as superoxide, nitric oxide (NO), thyl, peroxyl, and hydroxyl radical, play important roles in biological processes [3], and these oxygen-containing free radicals usually originate from losing a partial valence electron in electron transport chain at mitochondria. The terms "reactive oxygen species (ROS)" and "reactive nitrogen species (RNS)" contain not only free radicals but also active reagents such as hydrogen peroxide $\left(\mathrm{H}_{2} \mathrm{O}_{2}\right)$, singlet oxygen, and ozone $\left(\mathrm{O}_{3}\right)$ in living organisms.

ROS- and RNS-related oxidative stress resulted in disorders including serious aging, cancers, stroke, and diabetes [4, 5]. According to the previous reports, free radicals were also involved in neurodegenerative disease such as Alzheimer's disease and Parkinson's disease [6]. However, not all of the free radicals play harmful roles in human health. Nitric oxide (NO), generated by nitric oxide synthases (NOSs) when Larginine is converted to citrulline, serves as a cellular signaling molecule to regulate vasodilatation in blood vessels by 
activating guanylate cyclase, guanosine $3^{\prime}, 5^{\prime}$-monophosphate (cyclic GMP), and protein kinase G to relax smooth muscle via proteins phosphorylation [7].

In the last decade, metabolomics has progressed at a marvelous rate in the omics field. At an early stage of drug development, rat liver microsomes (RLMs) with specific cytochrome P450 (CYP450) activity were employed as an approach for the investigation of drug metabolism $[8,9]$. However, in drug discovery, it is time consuming, labor consuming, and expensive for the target molecules screening, pharmacodynamics, and pharmacokinetics followed by a series of in vivo and in vitro experiments. Fortunately, Volk et al. utilized on line electrochemical cell coupled with tandem mass spectrometer (EC-MS) to proceed with new instrumental analyses for oxidative metabolic molecules [1013]. Furthermore, Karst's group had extended the application of EC-MS to connect with liquid chromatographic (LC) system by a switch valve to be an EC-LC-MS [14]. The EC-LCMS system is not described as a continuous analysis but as an online sequential separation $[14,15]$. Moreover, Karst's group had utilized EC-MS techniques to simulate the metabolic pathways of drug such as a muscle relaxant tetrazepam and an antiarrhythmic drug procainamide $[14,16]$, to investigate and identify nucleotide oxidative products [17], and to analyze the oxidation of aniline with the formation of protein adducts [18]. Moreover, the cyclic voltammetry (CV) technique has been utilized to evaluate redox reaction of various biomolecules with their oxidative derivatives and to compare the oxidative products by different electrodes [1925].

In this study, we generated free radicals by Fenton reaction (Figure 1) to investigate the oxidative products or possible metabolites of nicotine with an online sequential analytic mass spectrometer system. Besides, Fenton reaction is an oxidative reaction occurring in mitochondria when ferrous ion $\left(\mathrm{Fe}^{2+}\right)$ reacts with $\mathrm{H}_{2} \mathrm{O}_{2}$ to generate free radicals such as the hydroxyl radical $\left(\mathrm{OH}^{*}\right)$ and superoxide anion. Meanwhile, superoxide dismutase (SOD) converts superoxide anion to $\mathrm{H}_{2} \mathrm{O}_{2}$. The total reaction is described as Haber-Weiss reaction (Figure 1), and the net reaction shows that superoxide anion and $\mathrm{H}_{2} \mathrm{O}_{2}$ are converted to oxygen, hydroxide ion, and hydroxyl radical. Avoiding contamination of electrodes and crack of electrochemical flow cell (max. pressure: 40 psi, Antec Leyden, Zoeterwoude, The Netherlands) $[14,15,17,18]$ caused by high pressure of HPLC, online electrodeless electrochemical oxidation (EEO) of free radicals generated by Fenton reaction was a novel technique to monitor the oxidative products and metabolites of nicotine. The EEO/HPLC separated system was equipped with electrospray ionization (ESI) and tandem mass spectrometer (MS/MS) to be an online EEO/HPLC ESI-MS/MS monitoring system. According to this EEO/HPLC ESI-MS/MS electrochemical equipment, the metabolic derivatives of nicotine [26] including cotinine, cotinine- $\mathrm{N}$-oxide, trans$3^{\prime}$-hydroxycotinine, nornicotine, norcotinine, nicotine- $N^{\prime}$ oxide, 4-oxo-4-(3-pyridyl)-butanoic acid, and 4-hydroxy-4(3-pyridyl)-butanoic acid were detected by tandem mass spectrometer.

$$
\begin{aligned}
& \text { Haber-Weiss reaction } \\
& \mathrm{Fe}^{3+}+\mathrm{O}_{2}^{-\bullet} \longrightarrow \mathrm{Fe}^{2+}+\mathrm{O}_{2} \\
& \mathrm{Fe}^{2+}+\mathrm{H}_{2} \mathrm{O}_{2} \longrightarrow \mathrm{Fe}^{3+}+\mathrm{OH}^{-}+\mathrm{OH}^{\bullet} \text { (Fenton reaction) } \\
& \text { Net reaction: } \mathrm{O}_{2}^{-\bullet}+\mathrm{H}_{2} \mathrm{O}_{2} \longrightarrow \mathrm{OH}^{-}+\mathrm{OH}^{\bullet}+\mathrm{O}_{2}
\end{aligned}
$$

FIgURE 1: The Haber-Weiss Reaction and Fenton reaction for hydroxyl free radical generation.

\section{Materials and Methods}

2.1. Chemicals. The reagents including hydrogen peroxide $\left(\mathrm{H}_{2} \mathrm{O}_{2}\right)$, nicotine, sodium acetate $\left(\mathrm{CH}_{3} \mathrm{COONa}\right)$, and potassium titanium oxide oxalate dehydrate $\left(\mathrm{C}_{4} \mathrm{O}_{9} \mathrm{~K}_{2} \mathrm{Ti}\right.$. $2 \mathrm{H}_{2} \mathrm{O}$ ) were provided by Sigma-Aldrich (St. Louis, MO, USA). The concentrated sulfuric acid, anhydrous methanol $(\mathrm{MeOH})$, and ferrous sulfate heptahydrate $\left(\mathrm{FeSO}_{4} \cdot 7 \mathrm{H}_{2} \mathrm{O}\right)$ were purchased from J. T. Baker (Phillipsburg, NJ, USA). The chemicals such as 1, 10-phenanthroline monohydrate $\left(\mathrm{C}_{12} \mathrm{H}_{8} \mathrm{~N}_{2} \cdot \mathrm{H}_{2} \mathrm{O}\right)$, acetic acid, and ammonium acetate $\left(\mathrm{NH}_{4}\right.$ $\mathrm{CH}_{3} \mathrm{COO}$ ) were purchased from Aldrich (Milwaukee, WI, USA). Distilled water was prepared to $18.2 \mathrm{M} \Omega \mathrm{cm}$ resistivity at $25^{\circ} \mathrm{C}$ by a Milli-Q system (Millipore, Bedford, MA).

2.2. The Concentration of $\mathrm{H}_{2} \mathrm{O}_{2}$ and $\mathrm{Fe}^{2+}$ Solutions. The concentration of $\mathrm{H}_{2} \mathrm{O}_{2}$ was determined by Sellers' method $[27,28]$. The reagent of potassium titanium (IV) oxalate $\left(\mathrm{K}_{2} \mathrm{TiO}\left(\mathrm{C}_{2} \mathrm{O}_{4}\right) \cdot 2 \mathrm{H}_{2} \mathrm{O} 354 \mathrm{mg}\right.$ was mixed with $2.72 \mathrm{~mL}$ of concentrated sulfuric acid and $3 \mathrm{~mL}$ of deionized water. After the diluted sulfuric acid solution was cooled to room temperature, it was adjusted to $10 \mathrm{~mL}$ by distilled water. Titanium(IV) solution $500 \mu \mathrm{L}$ was composed of different concentration of $\mathrm{H}_{2} \mathrm{O}_{2}$ solutions $(500 \mu \mathrm{L})$ and displayed yellow-orange complex detected by spectrophotometer at $400 \mathrm{~nm}$. The calibration curve was plotted by the intensities of spectrophotometer of different $\mathrm{H}_{2} \mathrm{O}_{2}$ concentration.

The concentration of ferrous ion was determined by ferroin indicator. Ferroin indicator includes both solution A (100 mg of 1,10-phenanthroline monohydrate dissolved in $100 \mathrm{~mL}$ distilled water) and solution B (25 g of ammonium acetate mixing with $15 \mathrm{~mL}$ distilled water and $70 \mathrm{~mL}$ acetic acid). The different concentrations of ferrous solutions ( $1 \mathrm{~mL})$ were prepared with $40 \mu \mathrm{L}$ solution A and $100 \mu \mathrm{L}$ solution B, respectively. After 25 mins, solutions were detected by spectrophotometer at $510 \mathrm{~nm}$. The calibration curve was plotted by the intensities of spectrophotometer at different ferrous sulfate concentrations.

2.3. The Preparation of Fenton Reaction and Nicotine. The reactive solution composed of $10 \mu \mathrm{L}$ nicotine (20 ppm), $90 \mu \mathrm{L}$ $\mathrm{H}_{2} \mathrm{O}_{2}(3 \%), 1890 \mu \mathrm{L}$ sodium acetate buffer ( $50 \mathrm{mM}, \mathrm{pH}$ 5.6), and $10 \mu \mathrm{L}$ ferrous sulfate heptahydrate $(100 \mathrm{mM})$ solutions was adjusted to $200 \mathrm{ppb}$ nicotine, $0.135 \% \mathrm{H}_{2} \mathrm{O}_{2}$, and $0.5 \mathrm{mM}$ $\mathrm{FeSO}_{4}$. The ultrahigh performance liquid chromatography (UHPLC) gradient was set at $30 \mathrm{mins}$ in one experiment. The sequential analyses were performed by injection of $10 \mu \mathrm{L}$ nicotinic oxidative mixture via the syringe of autosampler every 30 mins. 
TABLE 1: Metabolic derivatives of nicotine in EEO/ESI-MS/MS. The molecular formula, molecular weight, and $m / z$ of parent ion and daughter ions are listed.

\begin{tabular}{|c|c|c|c|c|}
\hline Name & Molecular formula & Molecular weight $(\mathrm{Da})$ & Parent ion & Daughter ions \\
\hline Nicotine & $\mathrm{C}_{10} \mathrm{H}_{14} \mathrm{~N}_{2}$ & 162.12 & 162.2 & $117,130,132$ \\
\hline Cotinine & $\mathrm{C}_{10} \mathrm{H}_{12} \mathrm{~N}_{2} \mathrm{O}$ & 176.22 & 177.7 & $80,119.5,134.5$ \\
\hline trans $-3^{\prime}$-Hydroxyl cotinine & $\mathrm{C}_{10} \mathrm{H}_{12} \mathrm{~N}_{2} \mathrm{O}_{2}$ & 192.21 & 194.0 & $106,118,134$ \\
\hline Nornicotine & $\mathrm{C}_{9} \mathrm{H}_{12} \mathrm{~N}_{2}$ & 148.20 & 148.7 & 80,130 \\
\hline Nicotine- $N$-oxide & $\mathrm{C}_{10} \mathrm{H}_{14} \mathrm{~N}_{2} \mathrm{O}$ & 178.23 & 179.0 & $120,130,148$ \\
\hline Norcotinine & $\mathrm{C}_{9} \mathrm{H}_{10} \mathrm{~N}_{2} \mathrm{O}$ & 162.19 & 162.5 & $67,93,119$ \\
\hline 4-Oxo-4-(3-pyridyl)-butanoic acid & $\mathrm{C}_{9} \mathrm{H}_{9} \mathrm{NO}_{3}$ & 179.17 & 180.2 & $81,99.5,108.6$ \\
\hline 4-Hydroxy-4-(3-pyridyl)-butanoic acid & $\mathrm{C}_{9} \mathrm{H}_{11} \mathrm{NO}_{3}$ & 181.07 & 182.2 & $84,91,122,136$ \\
\hline Cotinine- $N^{\prime}$-oxide & $\mathrm{C}_{10} \mathrm{H}_{12} \mathrm{~N}_{2} \mathrm{O}_{2}$ & 192.21 & 192.9 & 80,121 \\
\hline
\end{tabular}

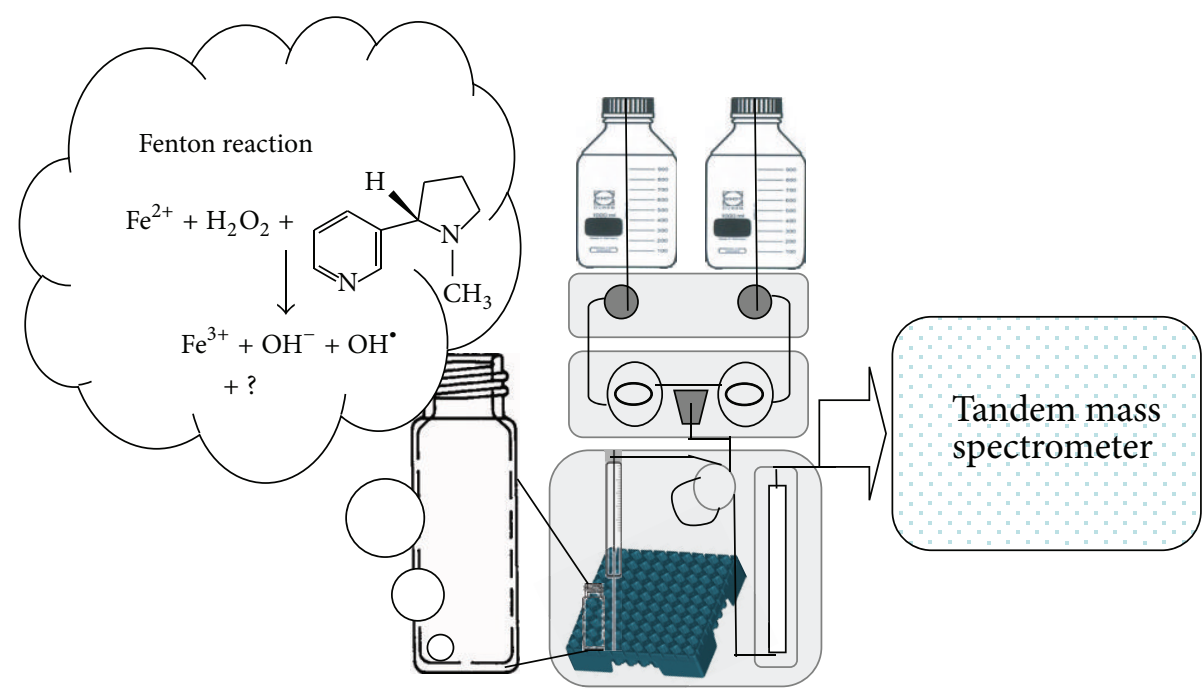

FiguRE 2: The schematic representations of experimental apparatus and Fenton reaction oxidative processes. Nicotine reacted with hydroxyl free radical in sample bottle and nicotinic oxidative products or metabolic derivatives were injected via syringe into analytic column in autosampler.

2.4. UHPLC and ESI-MS Analytic Conditions. Immediate online electrospray ionization mass spectrometry (ESI-MS) analyses of mixture with nicotine and Fenton reaction reagents were detected by a Thermo Finnigan TSQ Quantum Ultra Mass Spectrometer Analytic System (Thermo Fisher Scientific Inc., Waltham, MA, USA) equipped with the Micro ESI ion source which was set at $3.0 \mathrm{kV}$ coupled with Acella 1250 UHPLC system (Thermo Fisher Scientific Inc., Waltham, MA, USA). The oxidative mixture was subject directly into the UHPLC via Acella 1250 autosampler and was separated by Shiseido HPLC CAPCELL PAK C18 MGII column $(150 \mathrm{~mm}$ $\times 1.5 \mathrm{~mm}, 3.0 \mu \mathrm{m}$, Tokyo, Japan). The UHPLC flow rate was set at $250 \mu \mathrm{L} / \mathrm{min}$ (gradient pump). The mobile phases were composed of (A) $10 \mathrm{mM} \mathrm{NH}_{4} \mathrm{CH}_{3} \mathrm{COO}$ in water and (B) $10 \mathrm{mM} \mathrm{NH}_{4} \mathrm{CH}_{3} \mathrm{COO}$ in $100 \% \mathrm{MeOH}$ with a linear gradient followed from $5 \%$ (B) in $2 \mathrm{~min}, 5 \%-40 \%$ (B) in $20 \mathrm{~min}, 40 \%-$ $98 \%$ in $5 \mathrm{~min}, 98 \%$ (B) in $2 \mathrm{~min}, 98 \%-5 \%$ (B) in $0.1 \mathrm{~min}$, and $5 \%$ (B) in $2.9 \mathrm{~min}$. The nicotine, oxidative chemicals, and its metabolic derivatives were detected by mass spectrometer with applying voltage of $3.0 \mathrm{kV}$ in the positive ion mode, vaporizing and capillary temperature set at $300^{\circ} \mathrm{C}$ and $350^{\circ} \mathrm{C}$, respectively, sheath gas and aux gas pressure set at 35 and 10 , respectively, collision pressure at 1.5 , and collision energy adjusted at $25 \mathrm{~V}$. The survey scan mode was set at $\mathrm{m} / z 50-$ $250 \mathrm{Da}$ in the Quadrupole I chamber and nicotinic oxidative ions were detected and selected (intensity $>10^{4}$ ) in MS mode with three high intensity signals (data dependant scan), transferred into collision-induced dissociation (CID) chamber for MS/MS fragmentation and further detected in Quadrupole III chamber. The Xcalibur software (version 2.2, Thermo-Finnigan Inc., San Jose, CA) was utilized to control and adjust mass spectrometry instrument and data acquisition.

\section{Results and Discussion}

In this study, Fenton reaction generated free radical to react with nicotine and produced nicotinic oxidative products 


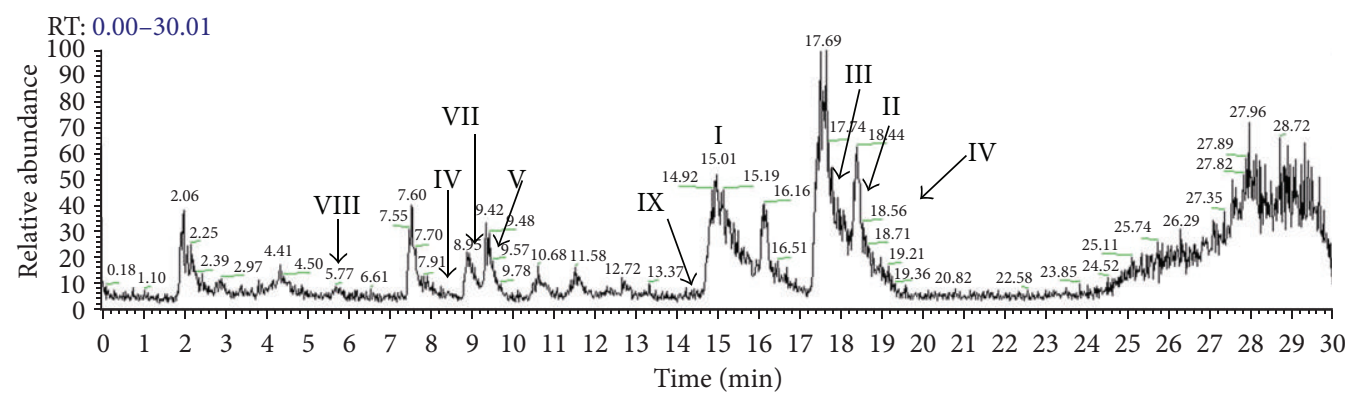

(a)

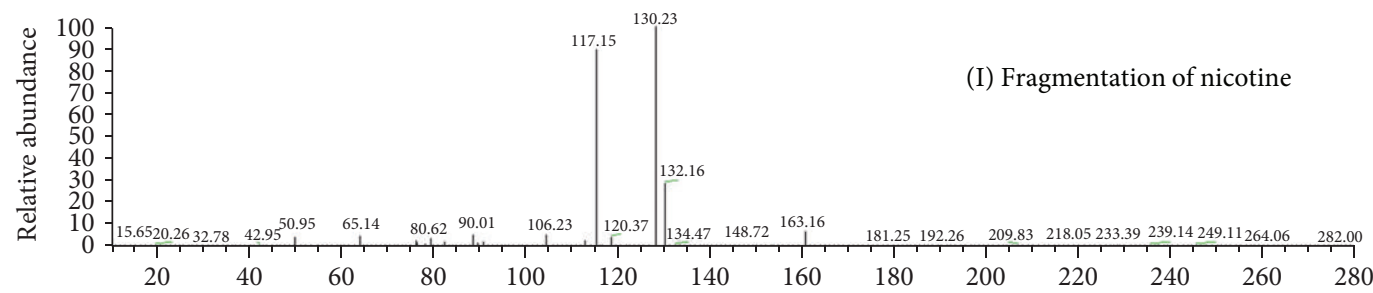

(b)

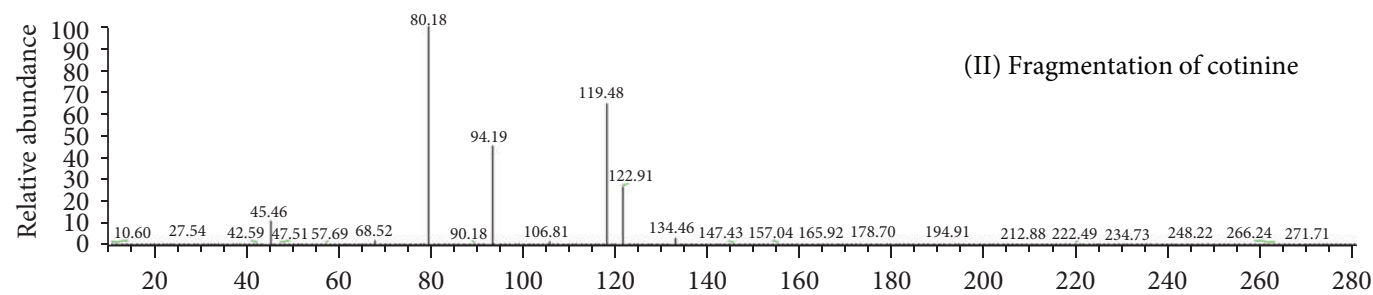

(c)

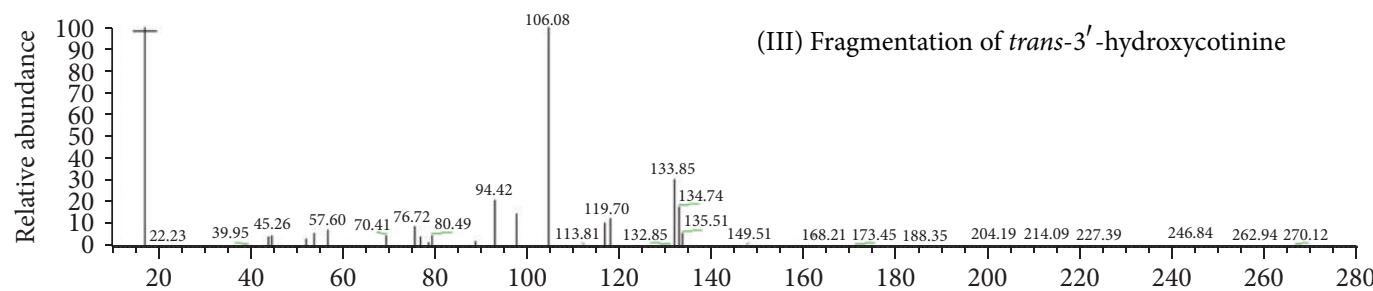

(d)

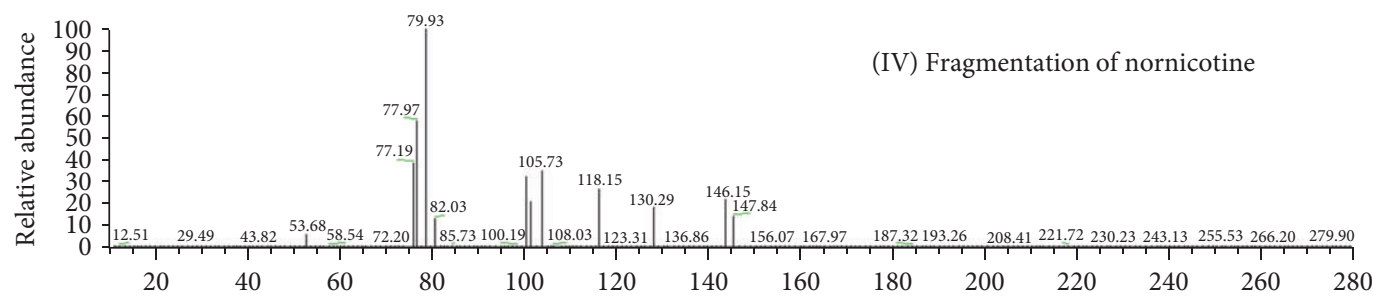

(e)

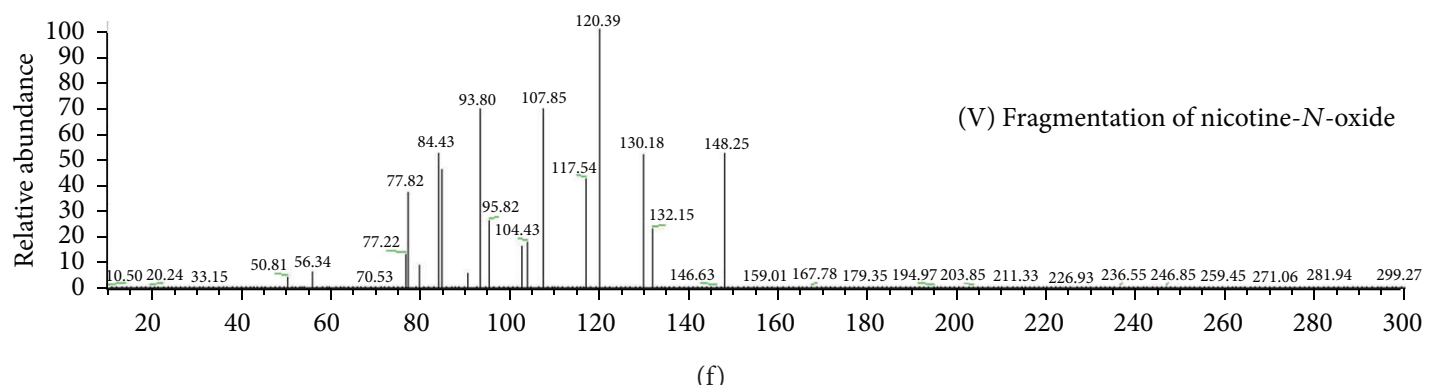

Figure 3: Continued. 


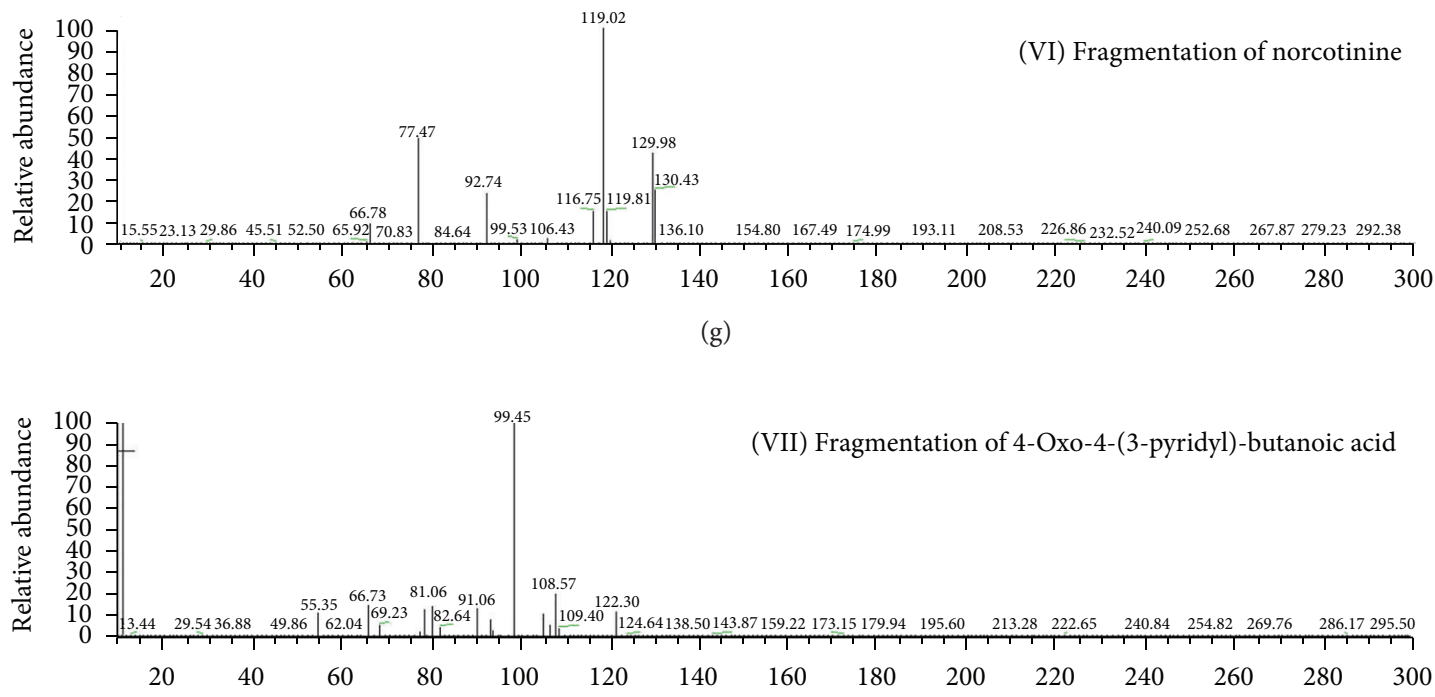

(h)

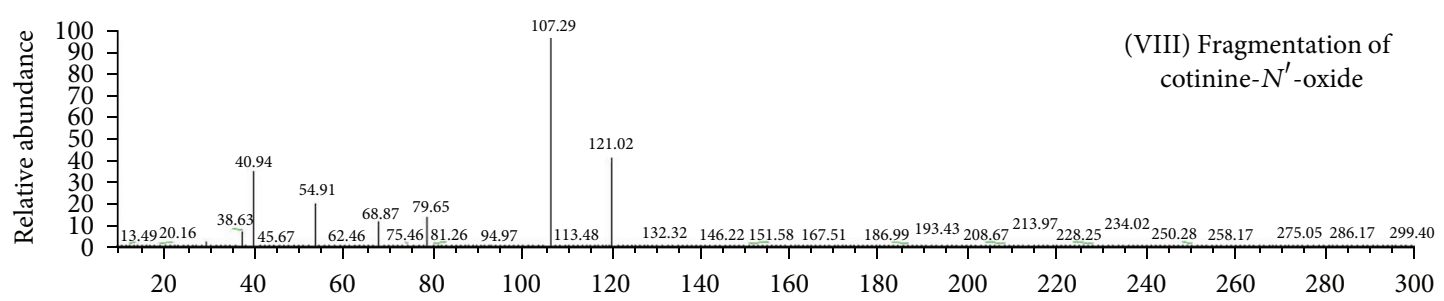

(i)

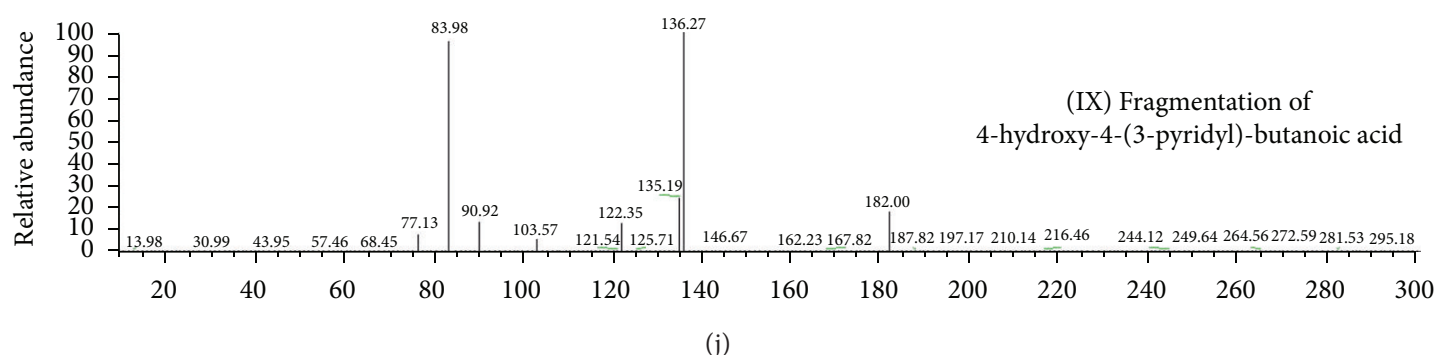

FIGURE 3: Electrodeless electrochemical oxidation (EEO) method coupled with UHPLC-MS/MS showed the spectra of the nicotine and its derivatives labeled with I-IX. The spectra displayed (a) base peak chromatogram and fragmentation pattern of nicotine (b), cotinine (c), trans-3'-hydroxyl cotinine (d), nornicotine (e), nicotin- $N$-oxide (f), norcotinine (g), 4-oxo-4-(3-pyridyl)-butanoic acid (h), 4-hydroxy-4-(3pyridyl)-butanoic acid (i), cotinine- $N^{\prime}$-oxide (j).

and derivatives. The electrodeless electrochemical oxidation (EEO) technique integrated with tandem mass spectrometer (EEO/UHPLC-ESI-MS/MS) for oxidative derivatives monitoring. By MS characterization, the results of nicotine and its derivatives were listed in Table 1.

3.1. Free Radical Generation from Haber-Weiss Reaction. As a catalytic reagent, $\mathrm{Fe}^{2+}$ reacted with $\mathrm{H}_{2} \mathrm{O}_{2}$ for producing hydroxyl free radical and oxygen. In the process of free radical generation, bubbles $\left(\mathrm{O}_{2}\right)$ were produced from the sample bottle. The Fenton reaction generating hydroxyl free radical was a side reaction of Haber-Weiss reaction. The chemical reaction formulas of Haber-Weiss reaction and Fenton reaction were listed in Figure 1.

3.2. EEO/UHPLC ESI-MS/MS Equipment for Nicotine and Its Oxidative Derivatives Monitoring. The schematic representation of experimental apparatus was showed in Figure 2. The mixture of free radical and nicotinic derivatives was injected by the syringe of autosampler into UHPLC system. In this technique, nicotine and its oxidative derivatives could be monitored in a run-to-run and time-dependent manner (data not shown). According to the previous studies [29-31], nicotinic metabolites detected in hair, urine, and plasma, and 


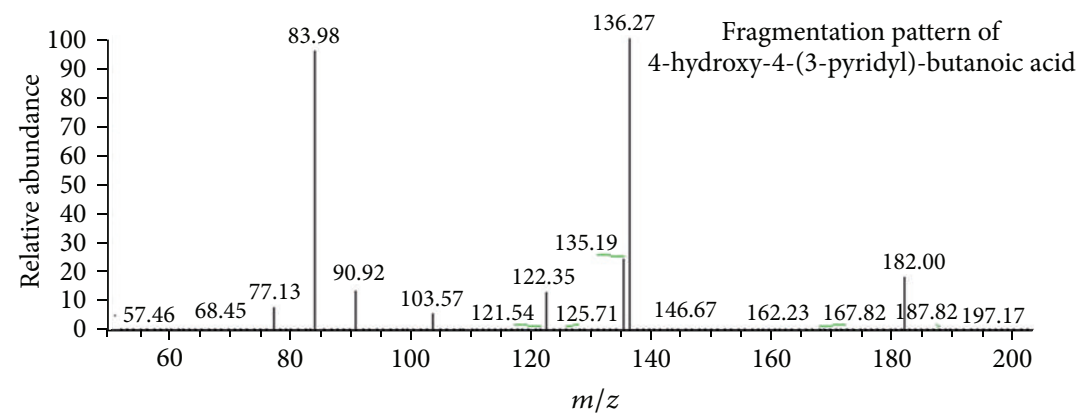

182.0: $[\mathrm{M}+\mathrm{H}]^{+}$, parent ion<smiles></smiles>

136.3:<smiles>O=C(O)C1CC1CC(O)c1cccnc1</smiles><smiles>CC(CC(=O)O)C(O)c1cccnc1</smiles><smiles>CC(CCC(C)C(=O)O)OO</smiles>

91:<smiles>O=C(O)CCCCC(O)c1cccnc1</smiles>

FIGURE 4: ESI-MS/MS fragmentation pattern spectrum of nicotinic derivative: 4-hydroxy-4-(3-pyridyl)-butanoic acid.

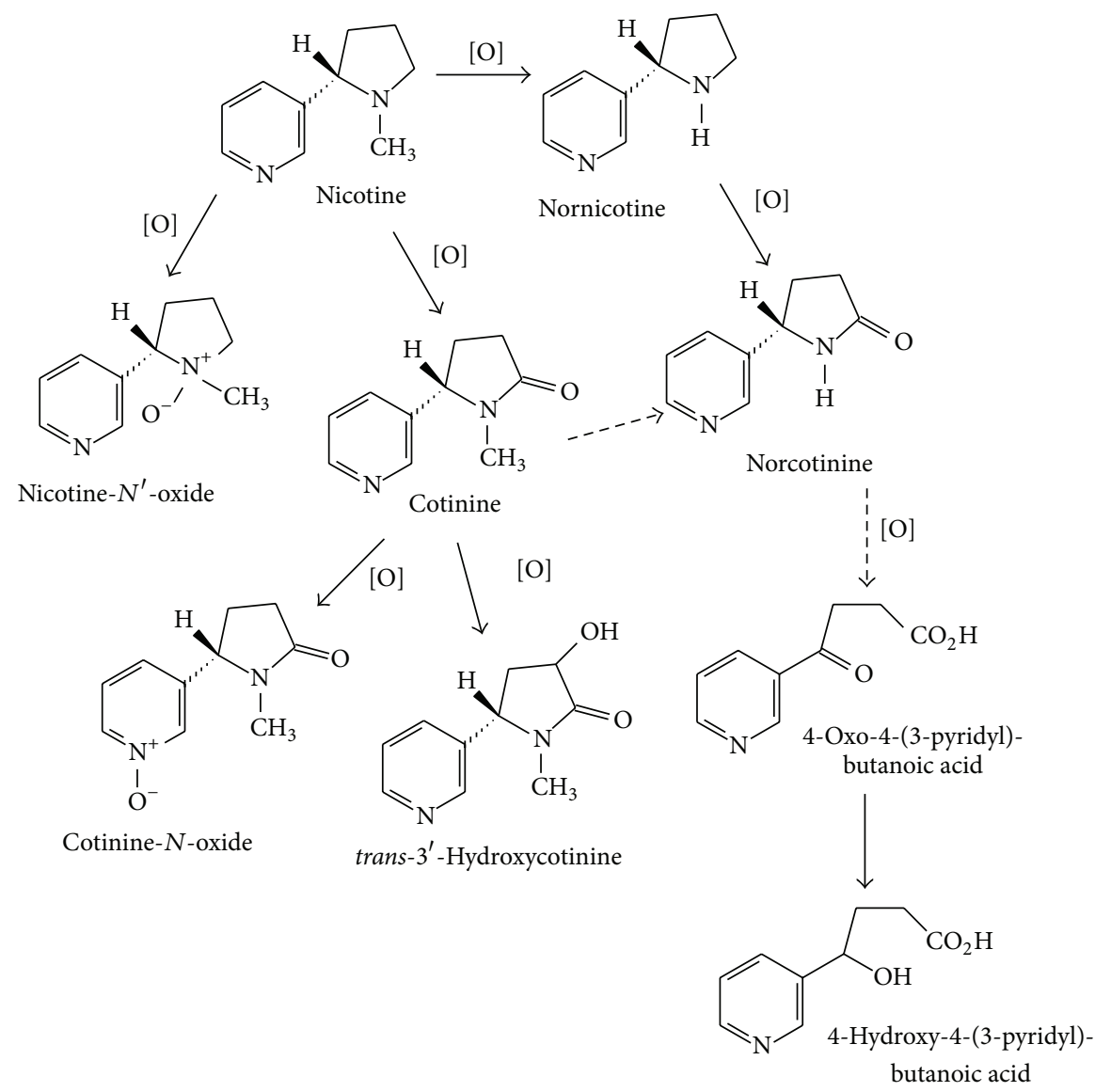

FIGURE 5: Pathways establishment of nicotine metabolism in electrodeless electrochemical oxidation (EEO) method coupled with UHPLC ESI-MS/MS. 
nicotine, 3-hydroxycotinine, or cotinine were selected as candidates. However, in the EEO/UHPLC ESI-MS/MS method, nicotinic metabolites including cotinine, cotinine- $N$-oxide, trans $-3^{\prime}$-hydroxycotinine, nornicotine, norcotinine, nicotine $N^{\prime}$-oxide, 4-oxo-4-(3-pyridyl)-butanoic acid, and 4-hydroxy4-(3-pyridyl)-butanoic acid were identified. The characterization of nicotine and its derivatives with name of derivatives, molecular formula, molecular weight, $\mathrm{m} / \mathrm{z}$ of parent ion, and daughter ions was listed in Table 1. Furthermore, UHPLC base peak chromatogram and the fragmentation pattern of each metabolite were shown in Figure 3. The fragmentation patterns of nicotine and its derivatives showed that each derivative was selected by mass spectrometer (depending on different molecular weights) and fragmentized by collision gas with kinetic energy in collision chamber. The fragments (daughter ions) of MS/MS data labeled with English vocabulary from (b) to $(\mathrm{j})$ were shown in Figure 3 and Table 1. We selected nicotinic metabolic reagent, 4-hydroxy-4-(3pyridyl)-butanoic acid, as a representative; the fragmentation pattern and predictive fragments of this metabolite were shown in Figure 4. According to Figure 3, in the fragmentation patterns of nicotine, cotinine, trans $-3^{\prime}$-hydroxycotinine, nornicotine, nicotine $N^{\prime}$-oxide, and cotinine- $N^{\prime}$-oxide, the spectra included the pyridinium ion at $m / z$ 80. Unfortunately, the pyridinium ion could not be observed at the fragmentation patterns of 4-hydroxy-4-(3-pyridyl)-butanoic acid and 4-oxo-4-(3-pyridyl)-butanoic acid. However, in the predictive fragments of 4-hydroxy-4-(3-pyridyl)-butanoic acid spectra, we could track the sources of each daughter ion. To sum up, EEO/UHPLC ESI-MS/MS method could be utilized to simulate the generation of metabolites and to monitor the changes in a time-dependent manner.

3.3. Establishment of Nicotinic Oxidative Pathway. According to the previous study [26] and the spectra shown in Figures 3 and 4 and Table 1, we could establish the oxidative pathway of nicotine. Moreover, the nicotinic oxidative metabolites characterized by EEO/UHPLC ESI-MS/MS could be integrated into the metabolism pathway, further shown in Figure 5. The arrow with a solid line directly showed the metabolic processes and the arrow with a dotted line indicated that this pathway required an intermediate. The label of [O] showed that the metabolite was generated via oxidative reaction.

\section{Conclusion}

The establishment of nicotinic metabolic pathway based on the electrodeless electrochemical oxidation (EEO) utilizing Fenton reaction to produce hydroxyl free radical to react with nicotine was demonstrated. The online EEO/UHPLC ESI-MS/MS analytic system setup could be employed in metabolomics study. Thus, nicotinic metabolic pathway was established via the characterized oxidative nicotinic derivatives. The tandem mass spectrometer is a powerful analytic instrument with characterization of nicotinic derivatives by fragmentation patterns. However, by the sequential analyses, this analytic technique could not immediately monitor the changes of nicotinic metabolites. In the future, Fenton reaction $\left(\mathrm{Fe}^{2+} / \mathrm{H}_{2} \mathrm{O}_{2}\right)$ has the potential to be utilized in exploring oxidative products of biomolecules including DNA, small molecular drugs, and formation of protein adducts.

\section{Conflict of Interests}

The authors declare that they have no conflict of interests in the study.

\section{Acknowledgments}

This study was supported by a Grant from the Kaohsiung Medical University Research Foundation (KMU-Q110023), cooperative plans between National Sun Yat-Sen University and Kaohsiung Medical University (NSYSUKMU 102-P029), and the National Science Council (NSC Grants 100-2113-M037-012-MY2), Taipei, Taiwan. The authos thank the Center for Resources, Research and Development of Kaohsiung Medical University for the supports of experimental instruments.

\section{References}

[1] K. H. Cheeseman and T. F. Slater, "An introduction to free radical biochemistry," British Medical Bulletin, vol. 49, no. 3, pp. 481-493, 1993.

[2] W. Li and K. Matyjaszewski, "Uniform PEO star polymers synthesized in water via free radical polymerization or atom transfer radical polymerization," Macromolecular Rapid Communications, vol. 32, no. 1, pp. 74-81, 2011.

[3] B. Poljsak and R. Dahmane, "Free radicals and extrinsic skin aging," Dermatology Research and Practice, vol. 2012, Article ID 135206, 4 pages, 2012.

[4] B. N. Ames, "Dietary carcinogens and anticarcinogens. Oxygen radicals and degenerative diseases," Science, vol. 221, no. 4617, pp. 1256-1264, 1983.

[5] H. Wiseman and B. Halliwell, "Damage to DNA by reactive oxygen and nitrogen species: role in inflammatory disease and progression to cancer," Biochemical Journal, vol. 313, part 1, pp. $17-29,1996$.

[6] R. A. Floyd, "Neuroinflammatory processes are important in neurodegenerative diseases: an hypothesis to explain the increased formation of reactive oxygen and nitrogen species as major factors involved in neurodegenerative disease development," Free Radical Biology and Medicine, vol. 26, no. 9-10, pp. 1346-1355, 1999.

[7] L. J. Ignarro, "Nitric oxide. A novel signal transduction mechanism for transcellular communication," Hypertension, vol. 16, no. 5, pp. 477-483, 1990.

[8] E. F. A. Brandon, C. D. Raap, I. Meijerman, J. H. Beijnen, and J. H. M. Schellens, "An update on in vitro test methods in human hepatic drug biotransformation research: pros and cons," Toxicology and Applied Pharmacology, vol. 189, no. 3, pp. 233-246, 2003.

[9] H. Yamanaka, M. Nakajima, K. Nishimura et al., "Metabolic profile of nicotine in subjects whose CYP2A6 gene is deleted," European Journal of Pharmaceutical Sciences, vol. 22, no. 5, pp. 419-425, 2004. 
[10] K. J. Volk, R. A. Yost, and A. Brajter-Toth, "On-line mass spectrometric insights into electrochemical reactions. Oxidation of thiopurines," Journal of the Electrochemical Society, vol. 137, no. 6, pp. 1764-1771, 1990.

[11] K. J. Volk, R. A. Yost, and A. Brajter-Toth, "Characterization of solution-phase and gas-phase reactions in online electrochemistry-thermospray tandem mass spectrometry," Journal of Chromatography A, vol. 474, no. 1, pp. 231-243, 1989.

[12] K. J. Volk, R. A. Yost, and A. Brajter-Toth, "On-line electrochemistry/thermospray/tandem mass spectrometry as a new approach to the study of redox reactions: the oxidation of uric acid," Analytical Chemistry, vol. 61, no. 15, pp. 1709-1717, 1989.

[13] K. J. Volk, M. S. Lee, R. A. Yost, and A. Brajter-Toth, "Electrochemistry/thermospray/tandem mass spectrometry in the study of biooxidation of purines," Analytical Chemistry, vol. 60, no. 7, pp. 720-722, 1988.

[14] A. Baumann, W. Lohmann, B. Schubert, H. Oberacher, and U. Karst, "Metabolic studies of tetrazepam based on electrochemical simulation in comparison to in vivo and in vitro methods," Journal of Chromatography A, vol. 1216, no. 15, pp. 3192-3198, 2009.

[15] A. Baumann, A. Faust, M. P. Law et al., "Metabolite identification of a radiotracer by electrochemistry coupled to liquid chromatography with mass spectrometric and radioactivity detection," Analytical Chemistry, vol. 83, no. 13, pp. 5415-5421, 2011.

[16] M. Odijk, A. Baumann, W. Olthuis, A. van den Berg, and U. Karst, "Electrochemistry-on-chip for on-line conversions in drug metabolism studies," Biosensors and Bioelectronics, vol. 26, no. 4, pp. 1521-1527, 2010.

[17] A. Baumann, W. Lohmann, S. Jahn, and U. Karst, "On-line electrochemistry/electrospray ionization mass spectrometry (EC/ESI-MS) for the generation and identification of nucleotide oxidation products," Electroanalysis, vol. 22, no. 3, pp. 286-292, 2010.

[18] D. Melles, T. Vielhaber, A. Baumann, R. Zazzeroni, and U. Karst, "Electrochemical oxidation and protein adduct formation of aniline: a liquid chromatography/mass spectrometry study," Analytical and Bioanalytical Chemistry, vol. 403, no. 2, pp. 377384, 2012.

[19] F. Boussicault and M. Robert, "Electron transfer in DNA and in DNA-related biological processes. Electrochemical insights," Chemical Reviews, vol. 108, no. 7, pp. 2622-2645, 2008.

[20] R. N. Goyal, V. K. Gupta, A. Sangal, and N. Bachheti, "Voltammetric determination of uric acid at a fullerene-C-60-modified glassy carbon electrode," Electroanalysis, vol. 17, no. 24, pp. 22172223, 2005.

[21] R. N. Goyal and A. Sangal, "Electrochemical investigations of adenosine at solid electrodes," Journal of Electroanalytical Chemistry, vol. 521, no. 1-2, pp. 72-80, 2002.

[22] R. N. Goyal, S. M. Sondhi, and A. M. Lahoti, "Investigations of electron-transfer reactions and the redox mechanism of $2^{\prime}$-deoxyguanosine- $5^{\prime}$-monophosphate using electrochemical techniques," New Journal of Chemistry, vol. 29, no. 4, pp. 587595, 2005.

[23] R. N. Goyal and A. Tyagi, "Investigations into the electrooxidation of guanosine $-5^{\prime}$-triphosphate at the pyrolytic graphite electrode," Analytical and Bioanalytical Chemistry, vol. 382, no. 7, pp. 1683-1690, 2005.

[24] S. C. B. Oliveira and A. M. Oliveira-Brett, "In situ DNA oxidative damage by electrochemically generated hydroxyl free radicals on a boron-doped diamond electrode," Langmuir, vol. 28, no. 10, pp. 4896-4901, 2012.

[25] A. M. Oliveira-Brett, J. A. P. Piedade, L. A. Silva, and V. C. Diculescu, "Voltammetric determination of all DNA nucleotides," Analytical Biochemistry, vol. 332, no. 2, pp. 321329, 2004.

[26] N. L. Benowitz, J. Hukkanen, and P. Jacob III, "Nicotine chemistry, metabolism, kinetics and biomarkers," Handbook of Experimental Pharmacology, vol. 192, pp. 29-60, 2009.

[27] C.-S. Chiou, C.-F. Chang, C.-Y. Chang et al., "Mineralization of polyethylene glycol in aqueous solution by hydrogen peroxide with basic oxygen furnace slag," Environmental Technology, vol. 25, no. 12, pp. 1357-1365, 2004.

[28] R. M. Sellers, "Spectrophotometric determination of hydrogen peroxide using potassium titanium(IV) oxalate," The Analyst, vol. 105, no. 1255, pp. 950-954, 1980.

[29] M. Dobrinas, E. Choong, M. Noetzli, J. Cornuz, N. Ansermot, and C. B. Eap, "Quantification of nicotine, cotinine, trans-3' hydroxycotinine and varenicline in human plasma by a sensitive and specific UPLC-tandem mass-spectrometry procedure for a clinical study on smoking cessation," Journal of Chromatography $B$, vol. 879, no. 30, pp. 3574-3582, 2011.

[30] G. N. Mahoney and W. Al-Delaimy, "Measurement of nicotine in hair by reversed-phase high-performance liquid chromatography with electrochemical detection," Journal of Chromatography B, vol. 753, no. 2, pp. 179-187, 2001.

[31] T. Tuomi, T. Johnsson, and K. Reijula, "Analysis of nicotine, 3-hydroxycotinine, cotinine, and caffeine in urine of passive smokers by HPLC-tandem mass spectrometry," Clinical Chemistry, vol. 45, no. 12, pp. 2164-2172, 1999. 

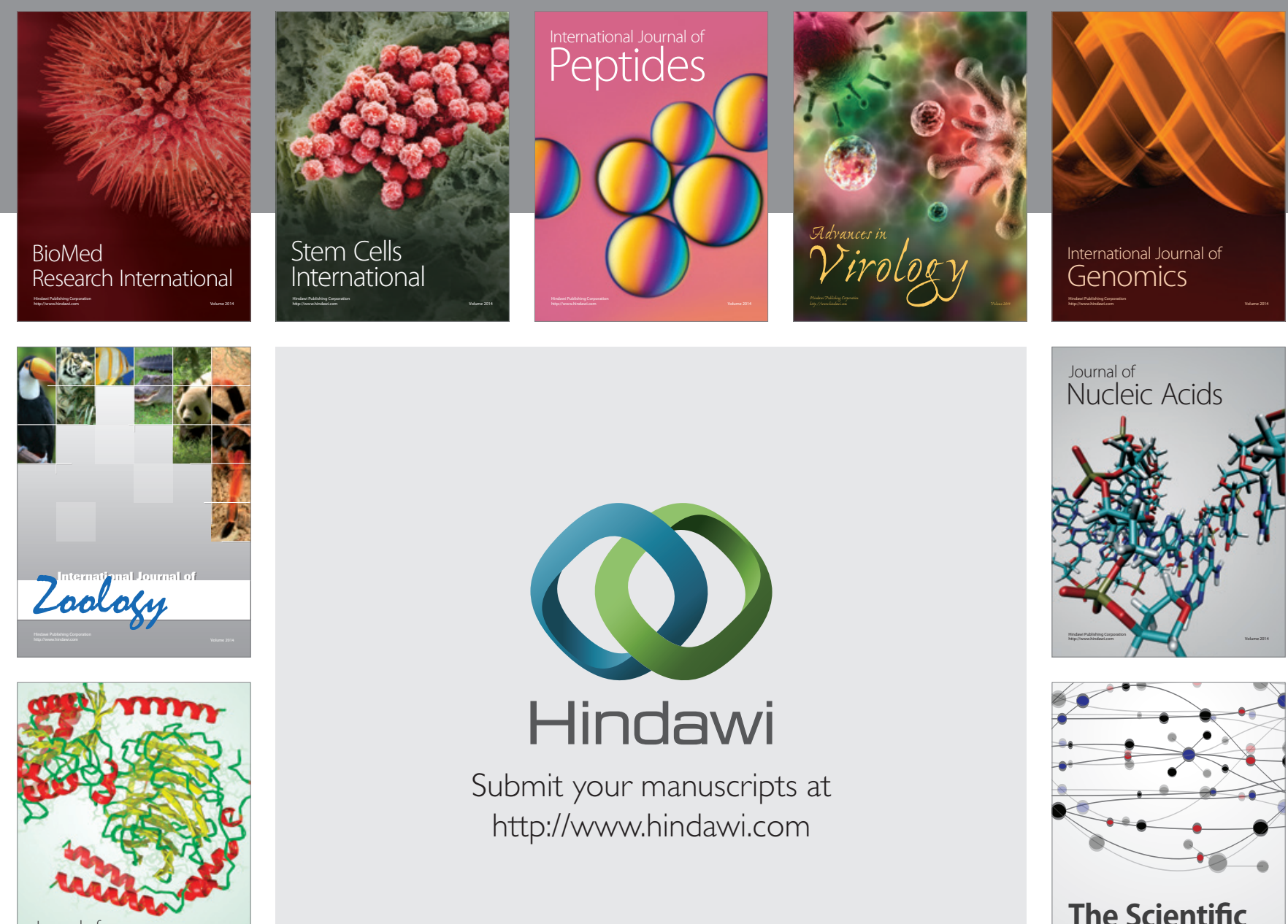

Submit your manuscripts at

http://www.hindawi.com

Journal of
Signal Transduction
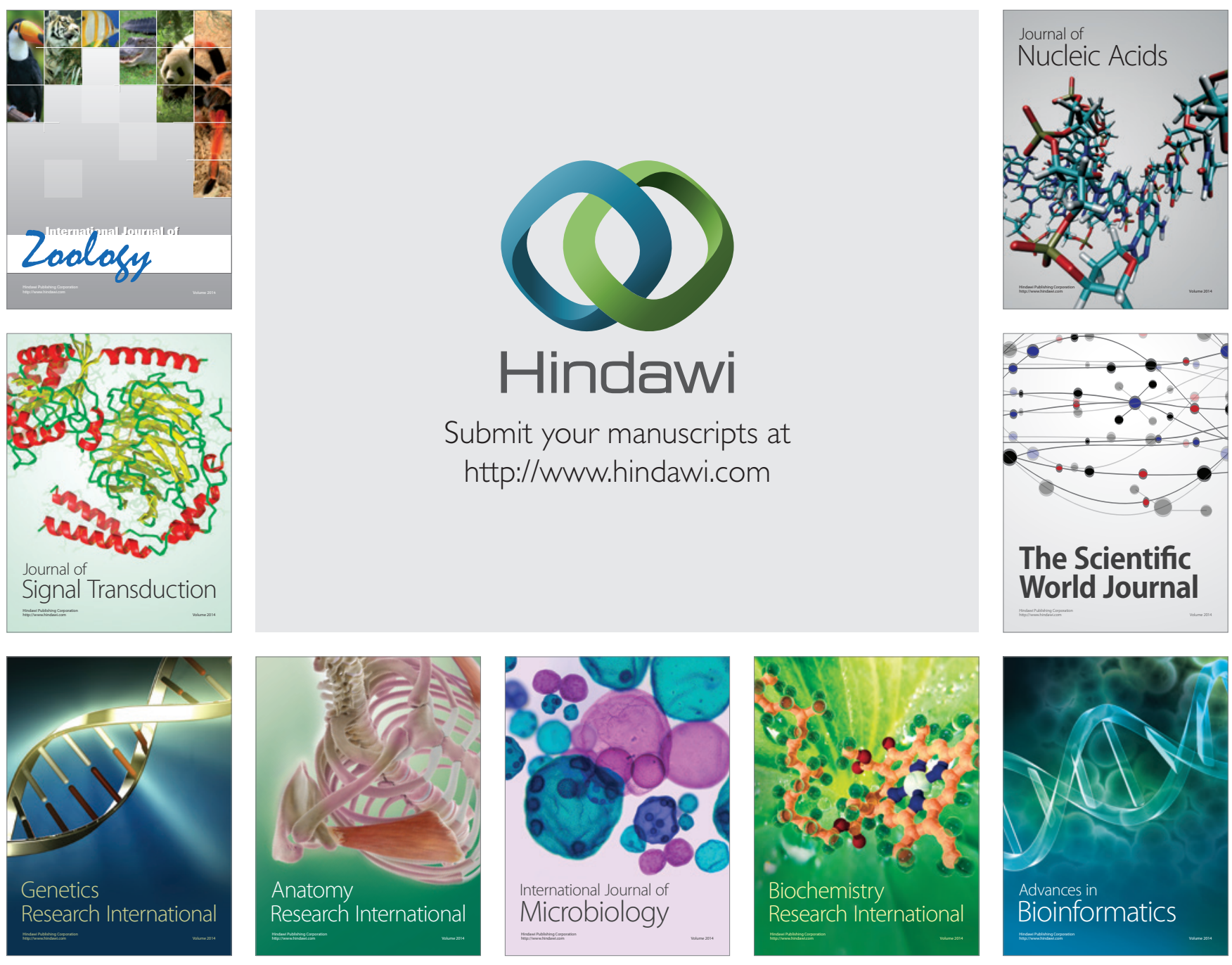

The Scientific World Journal
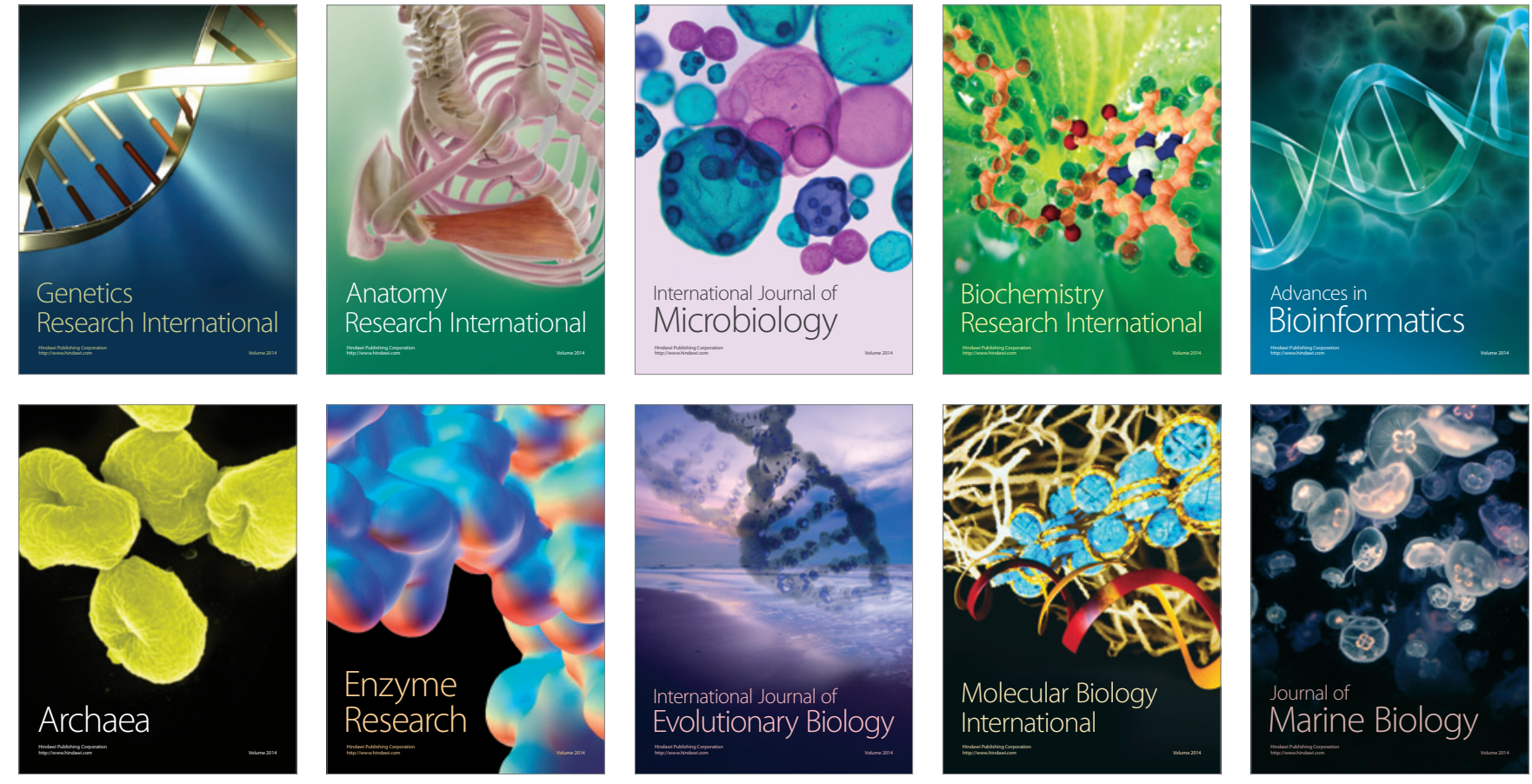